\title{
EDITORIAL
}

\section{Plagiarism and ethics of writing and publishing scientific research articles}

\author{
Chanya Padmaperuma ${ }^{1}$, Thilina Samarathunga ${ }^{2}$, Prasad Katulanda ${ }^{2,3}$ \\ ${ }^{1}$ Ministry of Health, Colombo, Sri Lanka \\ ${ }^{2}$ Diabetes Research Unit, Department of Clinical Medicine, Faculty of Medicine, University of Colombo, Sri Lanka \\ ${ }^{3}$ Department of Clinical Medicine, Faculty of Medicine, University of Colombo, Sri Lanka
}

The number of publications one produces has become a yardstick of recognition and prestige among the scientific community. Thus, to prevent themselves getting buried in obsolescence, researchers are prompted to publish more. This pressure for publication leads to an increase in research misconduct including plagiarism. This in turn, compromises the reliability and integrity of the research [1]. Recently, there has been a surge in the number of publications and so is the incidence of intellectual dishonesty.

Ensuring scientific integrity, authenticity and ethicality of publication is increasingly recognized as a role of the editors as gatekeepers for good and responsible research publishing [2]. For this purpose, the Committee on Publication Ethics (COPE) has introduced a set of principles for editors to deal with suspected misconduct [3]. While falsification and fabrication are some common forms of intellectual dishonesty, here we aim to discuss on the act of plagiarism.

\section{What is plagiarism?}

The term 'plagiarism' originates from the Latin word "plagium”, which means kidnapping. Therefore, in

\section{Author responsible for correspondence: \\ Prasad Katulanda \\ Professor in Medicine, Faculty of Medicine, University of Colombo, Consultant Endocrinologist, University Medical Unit, National Hospital of Sri Lanka \\ Email: prasad.katulanda@clinmed.cmb.ac.lk}

\section{DOI: http://doi.org/10.4038/cjms.v57i1.5016}

fD https://orcid.org/0000-0003-4313-7528 academia plagiarism refers to unethically copying another's ideas, work or words without giving the appropriate credit. The World Association of Medical Editors (WAME) defines plagiarism as, "the use of others' published and unpublished ideas or words (or other intellectual property) without attribution or permission, and presenting them as new and original rather than derived from an existing source" [4]. In addition, the global leading authority of regulating publication ethical practices, COPE has defined it as "when somebody presents the work of others (data, words or theories) as if they were his/her own and without proper acknowledgement” [3]. However, some of these definitions may not attribute to self-plagiarism.

\section{History of plagiarism}

During the medieval period, plagiarism had been very common. The first act of plagiarism was reported by the Roman poet Martial, where his work had been recited by another poet Fidentinus, and had been claiming credit for his work [5]. During the $17^{\text {th }}$ century where an individual's skills were honored, many renowned artists and authors copied other's ideas and work without consequences. Benjamin Franklin, Shakespeare and Leonardo Da Vinci are examples of famous figures of history who had plagiarized other's work and ideas as their own $[5,6]$. However, by the $18^{\text {th }}$ century copyright laws were implemented by the British parliament by enacting The Statute of Anne; Copyright Act 17098 Anne c.21[7].

\section{Types of plagiarism}

Depending on the authors' intent, plagiarism could be intentional or unintentional and it takes many different forms. 


\section{Direct plagiarism}

This is a form of intentional plagiarism where the author's work is a copied verbatim of other authors text without any acknowledgement or using quotation marks or giving credit to the original source $[1,9,10]$.

\section{Mosaic plagiarism (patchwork plagiarism)}

Here the writer borrows phrases and ideas from the original work without acknowledgement or replaces with synonyms. The end result is more or less the same as the original work $[1,9,10]$.

\section{Self-plagiarism (Duplication)}

This is where the author borrows significantly from his/ her own previous work. Here the author has used one's own data or text that has been published before without specifying the original source. Self-plagiarism is further classified as duplicate/redundant publication, augmented publication, segmented publication and text recycling [10,11].

- Duplicate/redundant publication - authors submit the same manuscript in different other journals unethically.

- Augmented publication - authors modify the previously published manuscript by editing the methodology, scope and by inserting additional data.

- Segmented publication - also known as "salami slicing" occurs when authors segment larger studies into several smaller studies.

- Text recycling - when large sections of the author's previously published work is copied in his/her new manuscript.

If an author decides to publish a translation of his/her manuscript published in a non-English journal to an English journal, the author is required to follow the requirements issued by the International Committee of Medical Journal Editors (ICMJE). Whether it is an actual scientific misconduct is a matter of controversy. It may violate the expectations of the reader who is trapped in the misconception of reading novel facts [10].

\section{Secondary source plagiarism}

This is when a researcher uses a secondary source but only cites the primary source [1].

\section{Invalid source plagiarism}

In this instance, the source is quoted or referenced incorrectly or inaccurately and the reader is misled. The main purpose of this is to increase the length of the list of references concealing his/her own inadequacy in research [1].

\section{Repetitive research}

This is repetition of data or text from a similar study with a similar methodology in a new study without proper ascribing the previous work [12].

\section{Replication}

Replication is when a single paper is submitted to multiple journals for publications [12].

\section{Misleading attribution}

This is either inaccurate or insufficient listing of authors or when authors cited in the paper had not made any contributions to the paper [12].

\section{Unethical collaboration}

When the results and outcomes of a certain work that are a result of a collaboration without citing the collaborative nature of the study or the participants involved [12].

\section{Complete Plagiarism}

An extreme scenario where, a researcher totally claims a study manuscript of another researcher and submits as his own [12].

\section{Why is plagiarism a problem?}

Reproducing and duplicating already existing and outdated facts is a waste of resources and time. In addition, it is unfair by the readers as they will be misled on crucial scientific information. The original author is deprived of the due credit for his genuine efforts. Consequently, intellectual dishonesty including plagiarism impedes progressive development of the scientific community and leads to confusion.

\section{Why is plagiarism on the rise?}

As stated previously, the pressure to publish is a key reason for rise in plagiarism. All-pervasive "Publish or Perish mantra" of the professional community seeking academic glory, financial pressure and personal ambitions of poorly educated individuals were identified as the root causes for this emerging predicament [13]. Lack of knowledge on plagiarism and citation practice in the scientific community is another major reason for increased plagiarism [1]. The ease with which chunks of text can be copied and pasted using computer software too leads to the rise in plagiarism. 


\section{Legal and ethical aspects of plagiarism}

Plagiarism can be punished and one can come under copyright infringement. Plagiarism violates those rights by copying the original work without giving due credit. However, plagiarism can be committed from sources that are out of copyright (in public domains) and not commit copyright infringement. Similarly, ideas and facts can be plagiarized as they are not protected by copyright. Although plagiarism is rarely witnessed being convicted under civil or criminal law, they are not unheard of. At one instance in 2012 in India, a researcher was imprisoned over allegations that he had plagiarized a colleague's research [14].

To ensure authenticity and credibility of scientific research, all authors should adhere to good publication practice and be true to personal ethics; honesty, fairness and reliability [15]. Moreover, editors and reviewers should maintain confidentiality of the submitted research and disclose any conflicts if present. Ethical behaviour should be strictly adhered, especially when it comes to medical research which stands out as the driving force of innovation and improving quality of life. Failure to adhere to ethical rules may cause adverse outcomes to the public safety and the trust in the scientific community [16].

\section{How to detect plagiarism?}

In the modern era where hundreds of thousands of print and electronic journals are published, it would be nearly impossible to detect plagiarism manually. Development of various software has revolutionized the screening for plagiarism. Software for plagiarism checking include iThenticate ${ }^{\circledR}$ [17], Plagiarism checker X [18], eTBlast [19], Turnitin [20] and CitePlag @Universität Konstanz [21].

Conversely, this is not entirely infallible as plagiarism detection tools don't detect plagiarism but assist the process by identifying duplication of phrases, sentences and paragraphs instead of the replication of core ideas. However, some software claim that they have developed a fingerprint-based approach to detect plagiarism of content to a certain extent [22]. Nonetheless, standard or common harmless phrases can be falsely detected as plagiarism by these software implicating the innocent. Yet, no software will ever be able to detect the 'intent' of plagiarism.

As per the COPE guidelines, if plagiarism is detected, the editor should reject the manuscript or if an act of selfplagiarism is detected, the editor may request for a resubmission with the plagiarized part corrected [11].

\section{How to avoid plagiarism}

Education on the appropriate skills and techniques to avoid and detect plagiarism should be encouraged from the very early stages of science education. Plagiarism could be avoided in the following ways [13].

- Following the scientific principles of fairness and guidelines to avoid plagiarism introduced by COPE.

- Paraphrasing in the right manner while adhering to scholarly expectations.

- Using quotation marks if six or more words are copied and citing references properly.

- Citing the sources to include full bibliographic information.

- Obtaining permission to reproduce copyright protected images.

- Checking for plagiarism before submitting to a journal by authors.

Finally, most respectable journal's editors would screen for plagiarism initially before the peer-review process, and this should be followed by all journals.

\section{Conclusions}

Plagiarism and other modes of scientific dishonesty are on the rise owing to the recent accelerated progression in scientific revelations and increase in online journals. Occasionally, plagiarism in an article could be subtle and unintentional. Hence, it is the duty of both the writer as well as the editor to be more vigilant and prevent 'the scientific dishonesty' which would harm the respect of scientific publications.

\section{References}

1. Sharma H, Verma S. Insight into modern-day plagiarism: The science of pseudo research. Tzu Chi Medical Journal 2020; 32(3): 240. doi: 10.4103/tcmj.tcmj_210_19

2. Marusic A. Importance of Ethical Publishing in Developing Countries. Acta Informatica Medica 2012; 20(1):4. doi: 10.5455/aim.2012.20.4-4

3. COPE: Committee on Publication Ethics [Online]. Publicationethics.org. 2021.

Available from: https://publicationethics.org/guidance/ Flowcharts. (Accessed 10 Apr 2021).

4. Recommendations on Publication Ethics Policies for Medical Journals -WAME [Online]. Wame.org. 2021.

Available from: https://wame.org/recommendations-onpublication-ethics-policies-for-medical-journals. (Accessed 10 Apr 2021). 
5. Historical Moments that Shaped Plagiarism [Online]. Turnitin.com. 2019.

Available from: https://www.turnitin. com/blog/5-historicalmoments-that-shaped-plagiarism. (Accessed 20 Aug 2021).

6. Lynch J. The Perfectly Acceptable Practice of Literary Theft: Plagiarism, Copyright, and the Eighteenth Century. 2006.

Available from: https://www.writing-world.com/rights/ lynch.shtml. (Accessed 20 Aug 2021).

7. The Statute of Anne: The First Copyright Statute [Online]. HistoryofInformation.com.

Available from: https://www.historyofinformation.com/ detail.php?entryid=3389. (Accessed 20 Aug 2021).

9. Masic I. Plagiarism in Scientific Research and Publications and How to Prevent It. Materia Socio Medica. 2014; 26(2): 141.

doi: 10.5455/msm.2014.26.141-146

10. Das N, Panjabi M. Plagiarism: Why is it such a big issue for medical writers? Perspectives in Clinical Research 2011; 2(2): 67. doi: $10.4103 / 2229-3485.80370$

11. Dhammi I, Ul Haq R. What is plagiarism and how to avoid it? Indian Journal of Orthopaedics 2016; 50(6): 581. doi: 10.4103/0019-5413.193485

12. Types of Plagiarism Infographic [Online]. Ithenticate.com. 2021.

Available from: https://www.ithenticate.com/resources/ infographics/types-of-plagiarism-research. (Accessed 10 Apr 2021).

13. Masic I. Ethical Aspects and Dilemmas of Preparing, Writing and Publishing of the Scientific Papers in the Biomedical
Journals. Acta Informatica Medica 2012; 20(3): 141. doi: 10.5455/aim.2012.20.141-148

14. Is Plagiarism Illegal? [Online]. Plagiarism.org. 2021. Available from: https://www.plagiarism.org/blog/2017/10/ 27/is-plagiarism-illegal. (Accessed 10 Apr 2021).

15. Fusch P, Ness L, Booker J, Fusch G. The Ethical Implications of Plagiarism and Ghostwriting in an Open Society. Journal of Social Change. 2017; 9(1). doi: 10.5590/JOSC.2017.09.1.04

16. Sinha R, Singh G, Kumar C. Plagiarism and unethical practices in literature. Indian J Ophthalmol. 2009; 57(6): 481-485.

17. iThenticate $^{\circledR}$. [Online] Ithenticate.com. 2021. Available from: https://www.ithenticate.com

18. Plagiarism Checker X. [Online] Palgiarismcheckerx.com. Available from: https://plagiarismcheckerx.com

19. Garner H. Combating unethical publications with plagiarism detection services. Urologic Oncology: Seminars and Original Investigations. 2011; 29(1): 95-99. doi: 10.1016/j.urolonc.2010.09.016

20. Turnitin [Online]. Turnitin.com. 2021. Available from: https://www.turnitin.com

21. CitePlag - Citation-based Plagiarism Detection [Online]. Universität Konstanz 2021.

Available from: https://www.isg.uni-konstanz.de/projects/ citeplag/

22. The Turnitin blog [Online]. Turnitin.com. 2021. Available from: https://www.turnitin.com/blog. (Accessed 12 Apr 2021). 